\title{
IMPACT OF URBAN GROWTH ON THE HISTORICAL AREA OF UMM AL QUWAIN, UAE
}

\author{
BOUZID BOUDIAF, JIHAD AWAD \& SAHAR MEKKY \\ Ajman University, United Arab Emirates
}

\begin{abstract}
The rapid urban growth in the United Arab Emirates (UAE) is phenomenal; the orientation of that urban development focuses on the modernization of towns and cities. This development was done to the detriment of historical areas, leading to their socio-cultural metamorphosis. The historic area of Umm Al Quwain is a case study, illustrating the challenges of its future. Our first research objective is to preserve the essential characteristics of the historical area, while injecting the desired new functional elements in a manner compatible with the traditional city structure. The second objective is to improve living standards in the historical area, especially with regard to infrastructure, sanitation and social facilities, providing a level of comfort equivalent to that of modern cities, but without destroying the traditional character of the area. This paper is structured in three main parts: the first one is more descriptive than analytic, and deals with the chronological development of the city. The second part, based on the strengths, weaknesses, opportunities and threats (SWOT) approach and the last on analyses of similar cases in the region, presenting the analysis of one zone of the historical area, with different suggestions of scenarios for the revitalization of the zone taken as a pilot project.

Keywords: architectural compatibility, historic area growth, medina, revitalization, Umm Al Quwain, United Arab Emirates, urban analysis, urban conservation, urban growth, urban planning.
\end{abstract}

\section{INTRODUCTION}

This paper narrates and explores the dichotomy between the preservation of a historical area and the extraordinarily rapid and unprecedented urban growth that can destabilize the existing harmony between the built environment and ecology, and metamorphose the character of most of the cities within the United Arab Emirates (UAE). These issues will be discussed through the case of Umm Al Quwain.

If a city is the place of conviviality, culture and concentration of opportunities for activities and services; the city is also the place for insecurity, precariousness, stress and all sorts of pollution. Today, typical sprawling housing developments, shopping centers, highways and other developments emerge from design principles that did not originate from any sense of the environmental context or to humankind's relation to it [1]. Many problems are caused by such uncontrolled urban growth.

This paper is structured in three main parts: the first one is more descriptive than analytic and deals with the characteristics of the Medina; the second part, after a very brief description of Umm Al Quwain, is based on the strengths, weaknesses, opportunities and threats (SWOT) analysis and on analyses of similar cases in the region, where we will present the different scenarios susceptible to revitalization of the selected area, as a pilot project. The third part concerns the evaluation of different scenarios, with a set of recommendations for the conservation of historic areas.

\section{CHARACTERISTICS OF THE TRADITIONAL CITY}

The traditional city, also called medina, is characterized by its vernacular architecture developed in harmony with the environment from the ecological and urban morphological points of views. In the case of the UAE, for defensive considerations, the fort is the main building: around it, we have groups of buildings. The fort usually includes a castle, providing 
a space on a high level to watch and control the situation. The structure of this traditional city is based on a controlled area with a hierarchy of roads, spaces and buildings. Narrow and steep alleyways divide the residential districts, at various widths ranging from 3-6 m. These led in turn to cul-de-sacs, about 2-4 m long, onto which the main dwelling doorways opened.

The organization of a traditional city is a compact aggregation of smaller and larger Elhara (quarters). Each El hara was equipped with open areas, access systems and shared facilities allocated to a group of collective and individual users. This organization is an organic, arborescent and animated urban structure, different from the rigid uniformity which is the product of the mechanical modes of urban planning.

The main characteristic of the traditional city is its urban design approach (compactness and global development, rather than a fragmented series of buildings seen as objects). From the archaeological point of view, the rural environment, through the organization and composition of the tribes and the physical environment had a significant role in defining the concept of the urban dwelling and its connections with its surroundings.

Each traditional city is governed by the architectural composition of a residential nature, which creates the city's style. In the case of the Emirates, the houses are determined mainly by some physical constraints, which are the climate and the availability of materials.

The harsh climate, the availability of construction materials and other geographical features have played intrinsic roles in shaping the physical characteristics of the vernacular architecture [2]. The simplest and maybe the oldest continuously used form of shelter throughout the deserts of the Arabian Peninsula is the tent. Tents are highly compatible with the nomadic way of life; they are also a symbol of national identity, because of their visual association with the traditional Bedouin tents.

In urban areas, we distinguish three types of houses: the buildings of the inner desert cities, that are adapted to the hot dry climate; the coastal buildings that are adapted to hot humid climate conditions; and the mountain buildings, determined mainly by the availability of materials (Fig. 1).

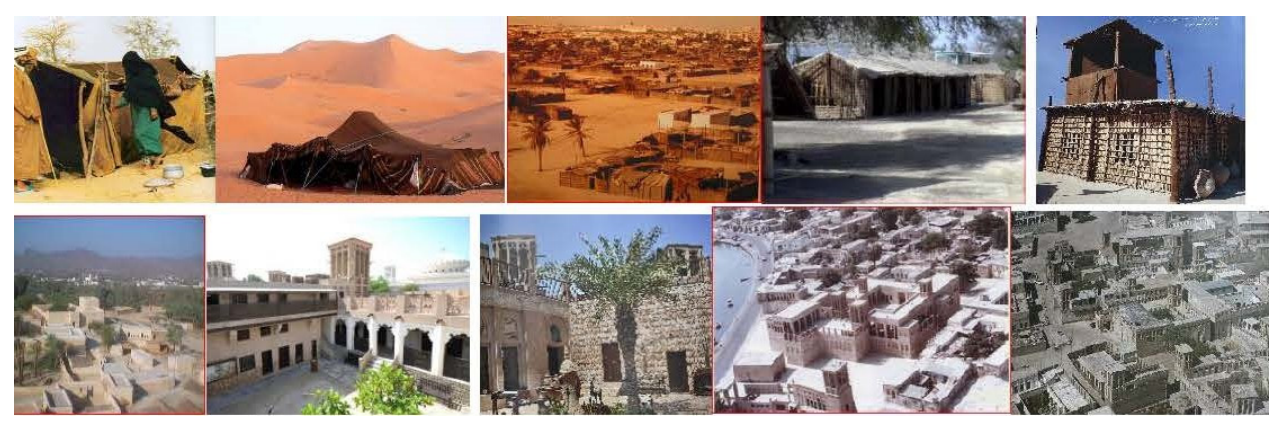

Figure 1: Types of houses or shelters in the UAE. These shelters are determined by the harsh climate and the availability of materials. (Source: Rashad Bukhash, president of the UAE Architectural Heritage Society.)

We distinguish the following types:

1. Tent considered as a temporary shelter and used principally by the Nomads.

2. Permanent houses built by using principally the coral from coastal areas, or stones in the houses in the mountains.

3. The Arish called Bait al Asaf, built principally by using trunks of palms. 


\section{FACTORS CONTRIBUTING TO THE GROWTH OF THE TRADITIONAL CITY}

The urban space of an old city has standard features: narrow streets, closed vistas, the open spaces given over to urban and social squares, but the traditions of buildings have given rise to wide local variations (Figs 2(a) and 7). These variations give an old city its dynamic character. The urban structure takes the form of a sequence of wide to narrow constructions. Open spaces inside the city gates narrow through connecting roads, and then open out again into social squares. This pattern is repeated throughout the city.

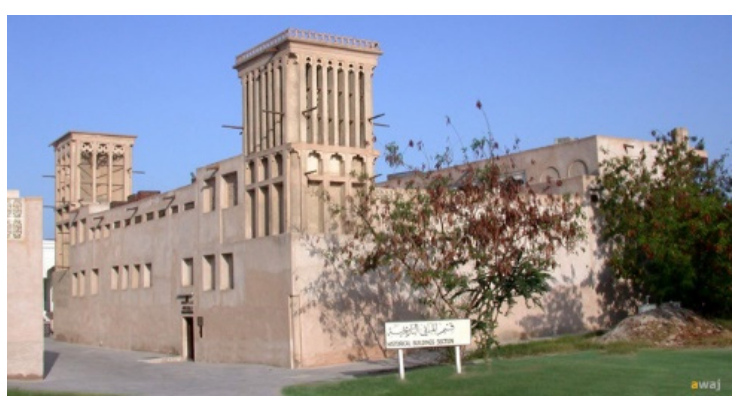

(a)

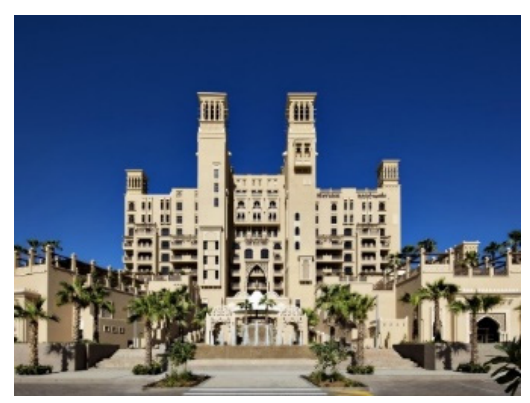

(b)

Figure 2: (a) A traditional house in a Fahidi District (Dubai) where it uses a wind tower (called Barajil); and (b) The Sheraton Hotel in Sharjah, where the Barajeels are just part of the décor. (Source: The authors.)

The mosque and the public activities are located around the social square. The social square acts as a connecting link between the mosque, the public activities, and the entrance of the housing cluster. A common phenomenon at the level of city planning is the minaret of a mosque seen as a landmark [3].

In the traditional buildings, the aesthetical issue was always present and achieved by using many elements that constitute the language of the traditional buildings. This included most, if not all, of the construction factors, starting with ventilation openings, walls, ceilings, columns, staircases and their handrails, etc. Colors also played an important role in the visual and aesthetical effect of buildings. Consideration was given to providing harmony between the building elements, masses; and at the same time, to the harmony between different buildings within one community [4].

\section{THE MAIN REASONS FOR DECAY OF THE MEDINA}

Most of the cities in the UAE emerged along the Gulf, justified for using the Gulf where fishing and the culture of pearls constituted the main source of income till the end of 1930. With the industrialization of the culture of pearls and the discovery of oil, UAE cities have been through a radical and unexpected metamorphosis by concentrating the decentralization of population and businesses into the cities, combined with large-scale exclusionary land-use zoning within the city, and increasing amounts of space given over to the demands of the motor car [5]. The consequences of these metamorphoses are the exodus and migration to the urban agglomerations, leading to the increase of population densities and due to this urban growth, a new kind of infrastructure and facilities developed, mainly by using the network as a grid to reshape the configuration of the historical towns (Fig. 3). 


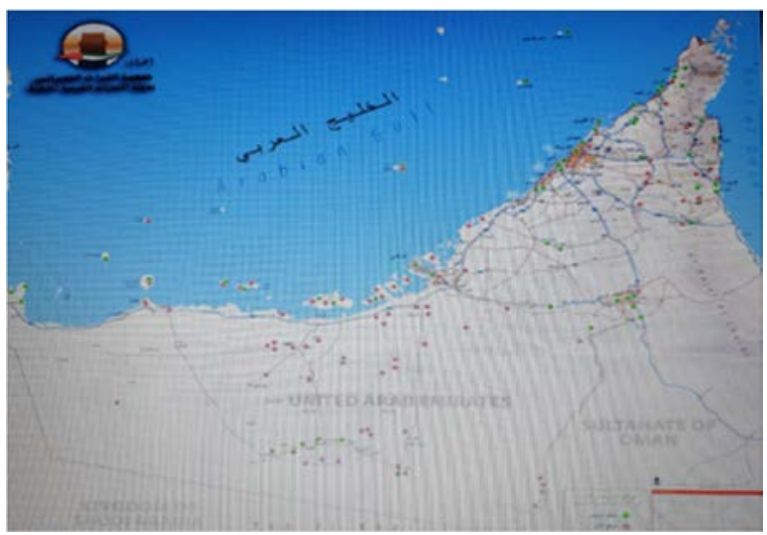

\begin{tabular}{|l|l|}
\hline City & $\begin{array}{l}\text { Archeological \& } \\
\text { Historical Sites }\end{array}$ \\
\hline Adu Dhabi & 800 \\
\hline Dubai & 750 \\
\hline Sharjah & 450 \\
\hline Ajman & 50 \\
\hline Oum Al Quawinn & 100 \\
\hline Ras Al Khaimah & 600 \\
\hline Fujairah & 500 \\
\hline Total & 3250 \\
\hline &
\end{tabular}

Figure 3: Through this map and table, we can appreciate the repartition of the archaeological and historical sites per Emirate. Clearly highlighted, most of these sites are located mainly along the Arabian Gulf. (Source: The UAE Architectural Heritage Society).

The dichotomy between the new and the historic areas affected both the social and physical characteristics of the built environment. The new urban form might be seen as aesthetically monotonous, social life has lost vitality because of the loss of a multitude of diverse experiences and activities that used to be in the urban environment. Unequal distribution of wealth among the different Emirates was one of the main issues of that segregation (physically and socially: Rashidiya in Dubai; Rolla in Sharjah and El Nakheel in Ajman). Nowadays, the three cities of Dubai, Sharjah and Ajman illustrate the phenomena of conurbation, which has negative impacts mainly in the congestion of circulation and the consideration of some areas as a dormitory district [6].

The consequences of this dichotomy are summarized as:

A. Physically, the rapid and unexpected urban growth leaded to the fragmentation of UAE cities, emphasized the sprawl related to development and the disproportion of the land use. The impacts of this physical growth are the acceleration of the deterioration, if not the dilapidation, of the traditional areas; the realization of massive and rapid public building, with new programs in different sectors (educational, cultural, economic, administrative, etc.). In the first decade of the union, most of the buildings were developed by taking into consideration both needs and family organization.

B. The socio-economic aspect is the second reason for the decay; the rapid industrial development was done with a lack of coordination, whether with the other sectors or between the Emirates, which ended by the fragmentation of the industrial tissue that was behind the rapid socio-economic changes. The adaptation and adoption of new technologies in with the unexpected urban growth made difficult the achievement of the standards of sustainability. The main aspects shaped whether the macro- or the microenvironments were based on functional issues.

C. The decay and the deterioration of the traditional built environment, due mainly to a misunderstanding of the traditional architecture, constitute the cultural reason that encouraged the speculation and the metamorphosis of the land use, which is dictated mainly by some financial considerations. 


\section{OUM AL QUAWINN AS A CASE STUDY}

Before 1971, year of the union of the seven Emirates and the proclamation of the UAE, there were social and physical organizations into agglomerations that were based on tribal consideration. The most powerful tribes since the late 19th century are Beni Yass, established in the Emirate of Abu Dhabi; and Al Qassimi in Ras Al Khaimah, and later on in Sharjah, too. The main cities in the UAE were developed along the coast (Fig. 3).

In the 18th century, Douar was the main agglomeration that was far out, at about $5 \mathrm{~km}$ from the city; and before moving to Umm Al Quwain city in the mid-18th century, the autochthone population moved and took refuge in an island called Maalah. The meanings of the Umm Al Quwain is "the mother" (land or home) of two forces, mainly the maritime and the terrestrial. Others relate the name to the land of the khors and justify it by the fact of being between the two khors (Khor Al Bayda and Khor Umm Al Quwain), or harbors (Fig. 4).

As in most of the traditional cities in UAE, it has a wall with its three towers "The Tower of the Yuwara" located on Bayda Creek, the "Infallible Tower" located in the center of the wall and the "Tower Al-Lazima-Mansour", located right on the Arabian Gulf (Fig. 5). The wall constituted the city limits; it was erected by Sheikh Abdellah Rashed Al Mulla in the mid-19th century, to protect the city from any terrestrial invasion. Inside the city, there were many forts and castles and the most important was the old fort palace, used as a residence of the ruler at that time, nowadays rehabilitated as a museum where many archaeological pieces are exhibited (Fig. 4) [7].

The area is characterized by elements representing the development of traditional architecture in the region (Fig. 4); both local stone and coral stone were the main materials used in the foundations and as structural elements, with fired blocks of bricks also used for the partition, and plaster for the inside finishes and the decorations.

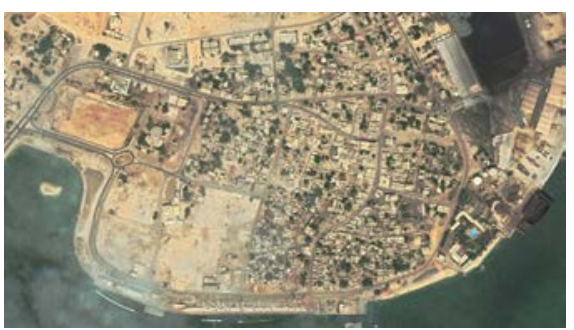

(a)

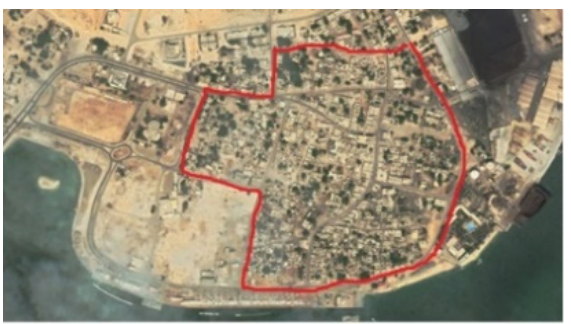

(b)

Figure 4: The historical area of Umm Al Quwain. The line in red indicates the area's limits. (Source: Google Earth.)

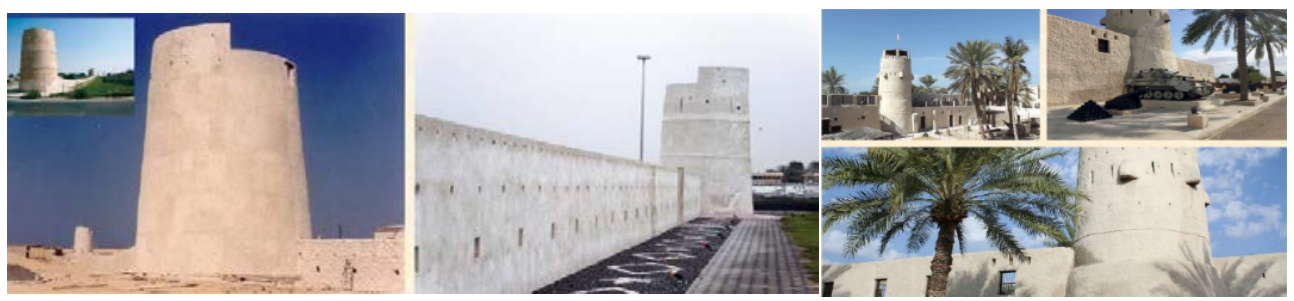

Figure 5: The wall of the city that was erected in the middle of the 19th century, with the three towers. (Source: Department of Tourism, Umm Al Quwain.) 


\subsection{Presentation of the area}

Historical buildings reflect the way of life of certain groups of people in a particular society and at a certain period of time. They support tangible and intangible objects expressing the way of life of a community. Historic buildings are sources of innovation, creation, and constitute a major component of culture and sustainable community development. The human scale of their buildings and urban elements are an expression of long chapters of history and events. The historical area seen in the map below constitutes the first nucleus of the city of Umm Al Quwain, composed of around 600 houses. Most of these houses are occupied nowadays by laborers from India and Bangladesh: the state of these buildings was bad, due to the lack of maintenance and overcrowded occupation of the rooms (5 to 10 times their capacity) (Fig. 6(a)).

Another reason that accelerated the decay and deterioration of the area is the fact that the autochthone moved to some modern districts, and even the laborers occupying these houses were taking these houses just as temporary, transitory shelters. Some of these houses were demolished in order to leave the place open for a modern, mid-rise or high-rise building.

Aware of the impact of proliferation of such type buildings in terms of the urban landscape and speculation, Sheikh Rashed Ben Ahmed Al Mullaa ordered that demolition to stop. The Department of Architecture at Ajman University was approached by the Department of Archaeology and Tourism, to make a survey of the existing houses. The area was divided into five zones: we were invited to develop scenarios for Zone A. The survey of houses and the scenarios were developed by students, under our supervision (Fig. 6(b)).

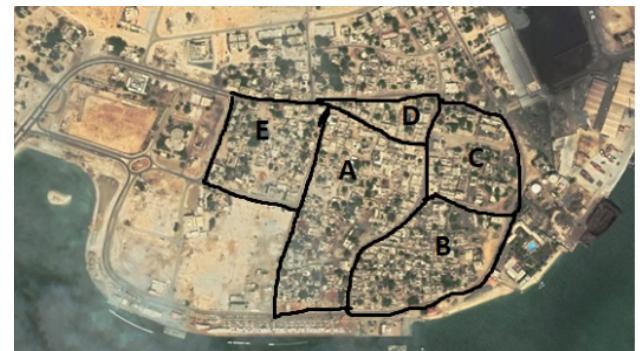

(a)

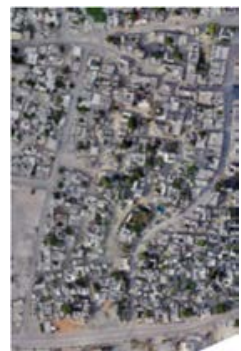

(b)

Figure 6: (a) Subdivision of the historical area into five zones. The subdivision was done by the Department of the Archaeology and Tourism of Umm Al Quwain in collaboration with the Historical Building Section in Dubai; and (b) The zone of study, Zone A. (Source: Google Earth.)

\subsection{Methodology}

After visiting the site and having several meetings with representatives of the Municipality, the Department of Archaeology and Tourism of Umm Al Quwain, the Historical Building Section at Dubai and the Architectural Heritage Society; our tasks as a Department of Architecture were to present a survey by recording and preparing documentation for the buildings in Zone A (Table 1), using the following criteria: State of the buildings; typology of the buildings; access to the buildings; land use; height of the buildings; values and architectural importance of the buildings (presence of any wind towers or buildings belonging to the Shaykhs "very important people (V.I.P) or rulers"; Mass and voids. 


\subsection{Analysis of Zone A}

Our analysis of Zone A is presented in Table 1.

Table 1: Main aspects taken into the analysis of the zone A. (Source: The authors.)

\begin{tabular}{|l|l|}
\hline $\begin{array}{l}\text { Criteria with } \\
\text { the keys }\end{array}$ & $\begin{array}{l}\text { Comments and observations } \\
\text { buildings: } \\
8-12 \mathrm{~m} \\
4-8 \mathrm{~m}\end{array}$ \\
$\begin{array}{l}\text { The development of the zone A is low as it is } \\
\text { the characteristics of most of the medina; we } \\
\text { can also notice the compactness for the } \\
\text { buildings; the buildings having more than one } \\
\text { level are situated at the edge of the zone and } \\
\text { nearby the main road in the area. }\end{array}$ \\
$\begin{array}{l}\text { State of the } \\
\text { Buildings: } \\
\text { Medium }\end{array}$
\end{tabular}


Table 1: Continued.

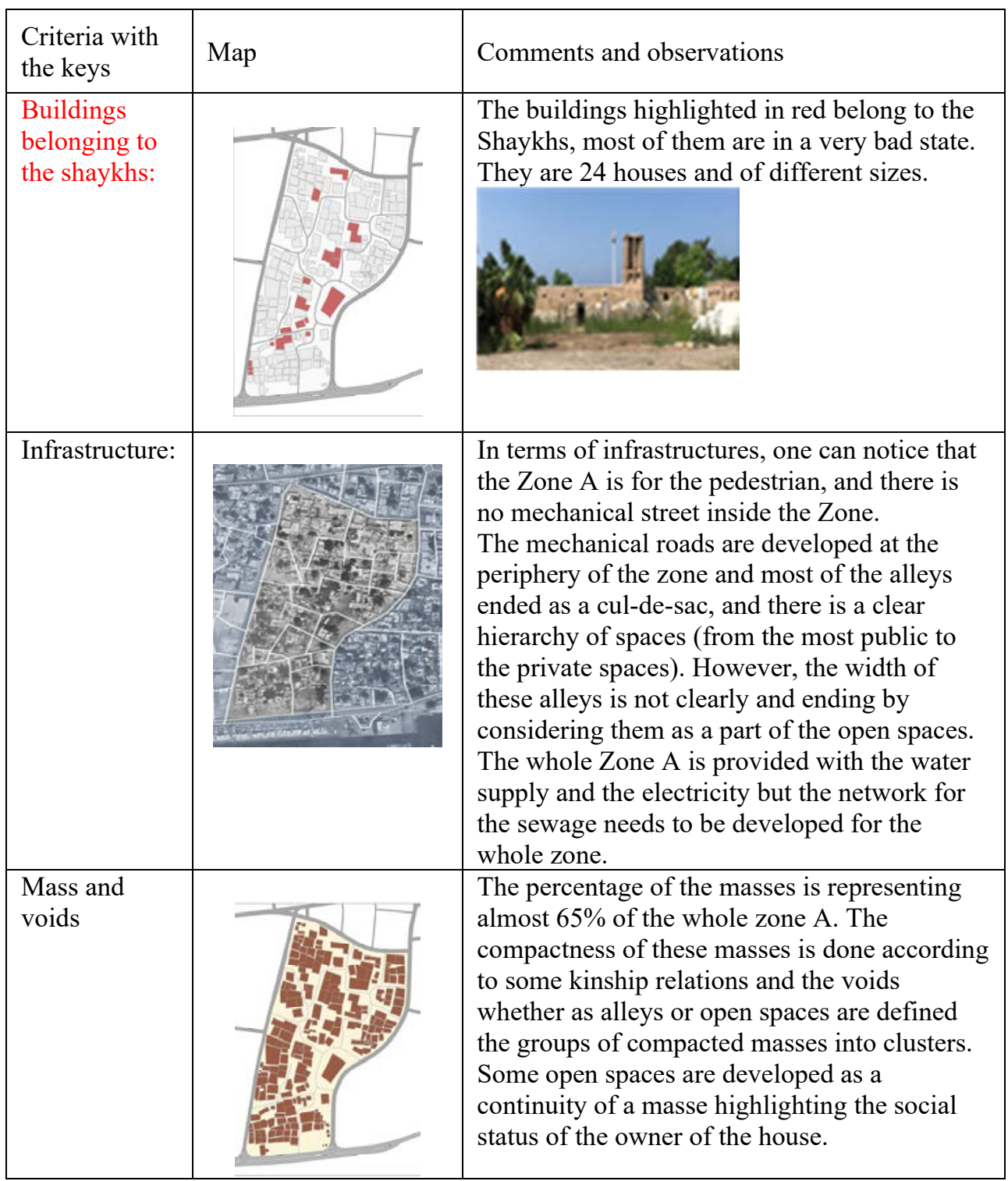

The main aspects highlighted in this analysis are: History: the age of some historic buildings went back to the mid-18th century, with the presence of the three towers and part of the wall that constituted the limits and gates of the Old City (Fig. 7). From the architectural point of view, the area is clearly characterized by the features of a traditional urban character, such as the use of the wind towers in some buildings, or the use of stone made of coral as a construction material (these two features are also indicators of the social status of the owner of the buildings). Due to its location, the area presents many potentialities for the development of some touristic-cultural activities (Table 2). 

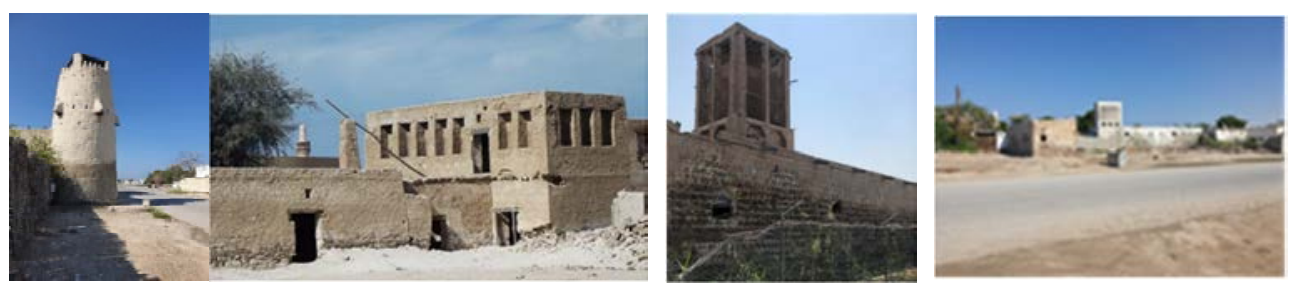

Figure 7: Photos showing the state of and the materials used in the tower and buildings (most of them are low-rise buildings with a wind tower, "Barajeel"). (Source: The authors.)

\subsection{Strategy}

Before the elaboration of a strategy for the area, each group of students, under our supervision, took on one case study. The 35 cases representing the historical areas, Medina, in the Arab world were presented. Those taken as case studies for further analysis are: Al Hafsia in Tunis, Jeddah, Marrakech, and Bastakia and Shandagha in Dubai. These case studies were debated in a seminar, leading us to discuss, with the participation of the representatives of the Architectural Heritage Society in the UAE, and then adopt the following strategy for the revitalization of the historical area of Umm Al Quwain:

A. Stop all demolitions of the buildings in the limited area;

B. Increase government support for urban heritage projects;

C. Involve some local families to support projects to preserve our urban heritage;

D. Development of heritage tourism as one of the main activities for the revitalization of the area and as a source of income for the population, and at the same time as an opportunity to sustain the know-how of traditional art crafts;

E. Promote awareness of the importance of preserving urban heritage, mainly for the young people, in a way to let them to be proud of what had been done by their predecessors and to highlight it as a part of their identity;

F. Use social media as a means for the promotion of this information;

G. Establish traditional crafts centers in the area;

H. Those buildings of great architectural or symbolic value must be listed as a heritage property.

\subsection{Scenarios}

As guidelines, each group established a design brief, in terms of recommendations for the revitalization of Zone A. The objective using the SWOT approach is to be able to develop a coherent scenario. The development of the scenarios was based mainly on sustainable community development [8].

A scenario of keeping the area as residential-only was rejected, due the fact of the centrality of the area within the city. Through the debate with and the feedback from the representative of the Department of Archaeology and Tourism, four dimensions had been identified, that are:

A. Social dimension: The diversity of users, with the objective to encourage the involvement and participation of the community in the process of the preservation of the tangible and intangible objects that reflect the character and the identity of the area; 
B. Economic dimension: The creation of a center of art and crafts leads to the creation of jobs, to attract investors, and to sustain the traditions and the know-how from one generation to another; ending by having created a specific and competitive area, at least at the city level;

C. Environmental dimension: One of the ways to avoid the sprawl of development and the proliferation of incompatible typologies will be achieved, through the revitalization of historical areas;

D. Cultural dimension: The sense of the place will be appreciated through the architectural language that will give character to the area and will be a source of attraction, and at the same time, of an emphasis of identity.

Each group of students had to develop all four scenarios: Commercial, Touristic, Cultural and Mixed.

\subsection{Presentation of the scenarios}

Table 2 shows the scenarios, highlighting the potentialities of the area, as developed on paper by our students.

Table 2: Scenarios highlighting the potentialities of the area. (Source: The authors.)

\begin{tabular}{|c|c|c|}
\hline $\begin{array}{l}\text { Scenario with } \\
\text { the keys }\end{array}$ & Map & Characteristics \\
\hline $\begin{array}{l}\text { Scenario 1: } \\
\text { Commercial: } \\
\text { Masses for: } \\
\text { Commerce } \\
\text { Mosques } \\
\text { Residential } \\
\text { Symbolic } \\
\text { Motel } \\
\text { Administration }\end{array}$ & 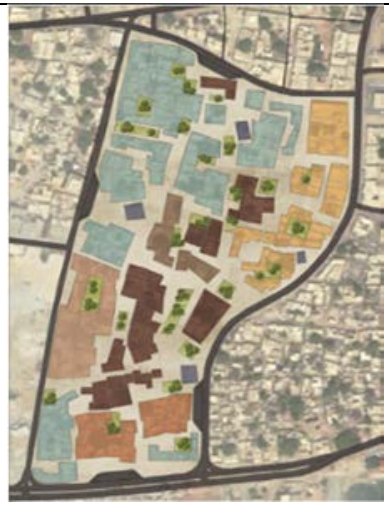 & $\begin{array}{l}\text { The activities in this scenario are } \\
\text { commercial but in relation with the } \\
\text { traditions and customs: the shops will } \\
\text { developed as a bazar and shops as } \\
\text { workshops to be more attractive. The } \\
\text { objectives from the workshop is to } \\
\text { attract the tourist, to insure the } \\
\text { transmission of the know-how from one } \\
\text { generation to another ending by } \\
\text { involving the owners of the shops to be } \\
\text { more attentive and will take about the } \\
\text { environment as considered as their } \\
\text { source of income. }\end{array}$ \\
\hline
\end{tabular}


Table 2: Continued.

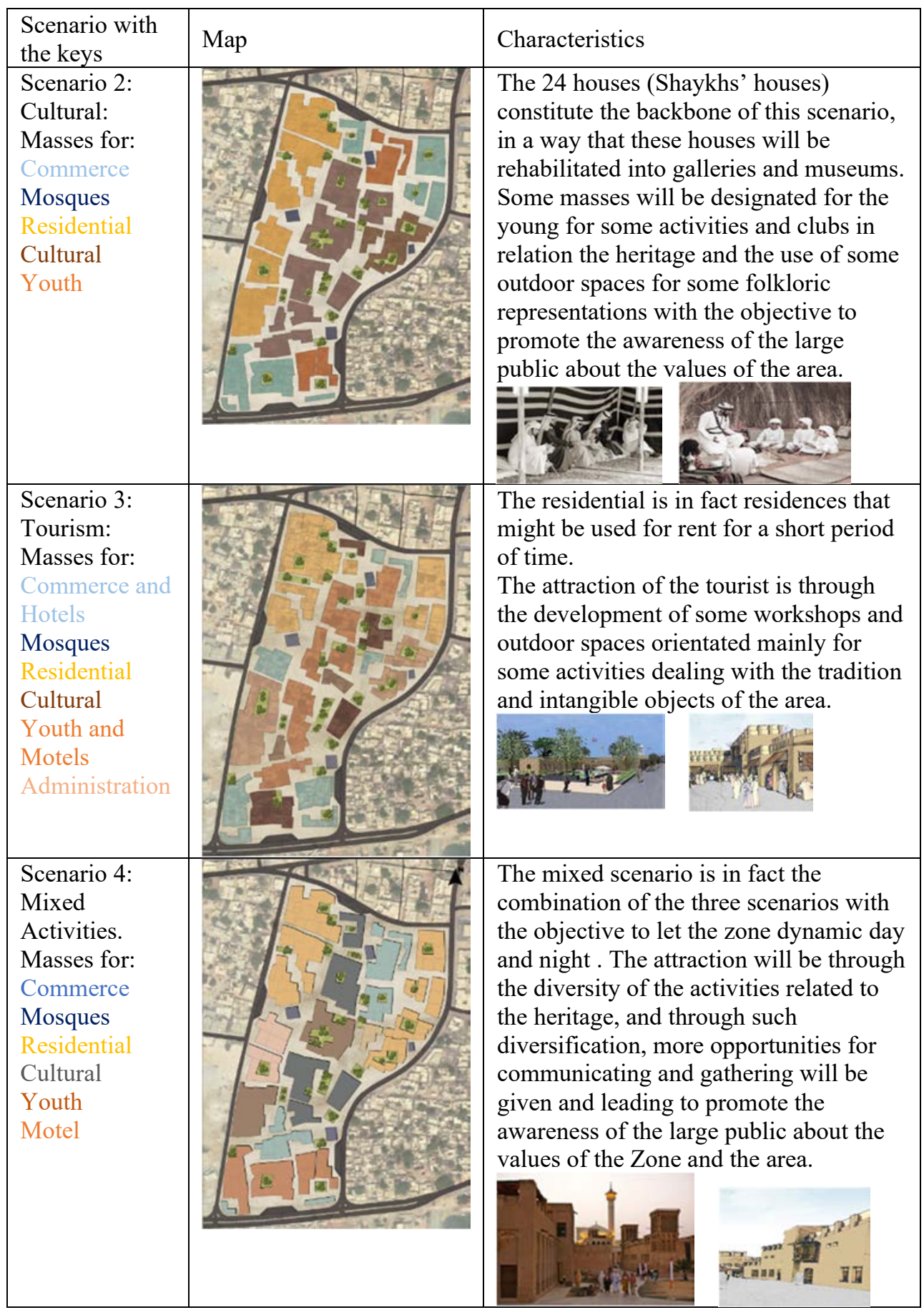




\section{CONCLUSIONS}

This paper provides us with an opportunity to highlight the characteristics of the Medina and the main reasons for its decay. The zone of study, Zone A, constituted a pilot project inscribed in an historical area. The purposes of an intervention in this zone are: to stop the demolition of traditional, historic buildings; to avoid speculation in the area; and avoid the proliferation of mid- and high-rise buildings. The criteria for analysis of this zone were established from case analyses presented by university students. The different scenarios were developed by taking into consideration four dimensions leading to sustainable community development. The development of these scenarios was to demonstrate that historic zones can participate in the dynamism and the development within a city, by keeping its important characteristics and identity, in order to overcome the challenges of contemporary cities in a sustainable way.

\section{ACKNOWLEDGEMENTS}

The authors would like to thank the President of the Architecture Heritage Society for his availability and encouragement and the students for recording the document and for their perseverance.

\section{REFERENCES}

[1] Taileb, A., Arbaoui, A. \& Boudiaf, B., Understanding urban systems and sprawl in the U.A.E.: Case studies from Ajman, Sharjah, Dubai and Abu Dhabi. Instant Cities: Emergent Trends in Architecture and Urbanism in the Arab World, American University of Sharjah: Sharjah, UAE, 2008.

[2] Radoine, H., Planning paradigm in the medina: Order in randomness. Planning Perspectives Journal, 26, p. 4, 2011.

[3] Hakim, B., Arabic Islamic Cities: Building and Planning Principles, Routledge: Oxford, 2006.

[4] Dubai Municipality, Elements of Traditional Architecture in Dubai, Dubai Press: Dubai, 1996.

[5] Boudiaf, B., The impact of the tourism on the revitalization of the historic centre. Presented at the International Conference on Protecting Cultural Heritage of the Muslim World, IRCICA and ISESCO, Istanbul, Turkey, 2017.

[6] Jehad, A., Arar, M. \& Boudiaf, B., Urban growth in the U.A.E.: Challenges and metamorphoses, in capital cities, wicked problems: Best practices in planning and policy response mechanisms. 10th Sharjah Urban Planning Symposium, American University of Sharjah: Sharjah, UAE, 23-25 Nov. 2008.

[7] Department of Archaeology and Tourism of Umm Al Quwain, 2019.

[8] Cimadomo, G., Community participation for heritage conservation. Presented at AESP (Association for European School of Planning), Wroclaw University of Technology, Warsaw, 2015. 